\title{
WHO BENEFITS FROM OBTAINING \\ A GED? EVIDENCE FROM HIGH SCHOOL AND BEYOND
}

\author{
Richard J. Murnane \\ John B. Willett \\ John H. Tyler \\ Working Paper 7172 \\ http://www.nber.org/papers/w7172 \\ NATIONAL BUREAU OF ECONOMIC RESEARCH \\ 1050 Massachusetts Avenue \\ Cambridge, MA 02138 \\ June 1999
}

We thank the Rockefeller, Russell Sage, Smith Richardson, and Spencer Foundations for supporting the research that led to this paper. All opinions expressed are those of the authors and not those of the National Bureau of Economic Research.

(C) 1999 by Richard J. Murnane, John B. Willett, and John H. Tyler. All rights reserved. Short sections of text, not to exceed two paragraphs, may be quoted without explicit permission provided that full credit, including $(\mathcal{C}$ notice, is given to the source. 
Who Beneftis from Obtaining a GED?

Evidence from High School and Beyond

Richard J. Murnane, John B. Willett, and John H. Tyler

NBER Working Paper No. 7172

June 1999

JEL No. I21, J24

ABSTRACT

This paper examines the value of the GED credential and the conventional high school diploma in explaining the earnings of 27-year-old males in the early 1990s. The data base is the High School \& Beyond sophomore cohort.

We replicate the basic findings of prior studies that implicitly assume the labor market value of the GED credential does not depend on the skills with which dropouts left school. We show that these average effects mask a more complicated pattern. Obtaining a GED is associated with higher earnings at age 27 for those male dropouts who had very weak cognitive skills as tenth graders, but not for those who had stronger cognitive skills as tenth graders.

Richard J. Murnane

Harvard Graduate School of Education

6 Appian Way -- Gutman 465

Cambridge, MA 02138

and NBER

richard_murnane@harvard.edu

John H. Tyler

Box 1938

Brown University

Providence, RI 02912

John_Tyler@Brown.EDU
John B. Willett

Harvard Graduate School of Education

Longfellow Hall

Appian Way

Cambridge, MA 02138

john_willett@harvard.edu 
In the last decade at least 13 studies have examined whether acquisition of the General Educational Development certificate (GED), the school leaving credential most commonly available to school dropouts, improves their labor market outcomes. ${ }^{1}$ A critical unstated assumption underlying all of these studies is that the labor market value of the GED credential does not depend on the skills with which dropouts left school. Adolescents drop out of high school with different skill levels and for different reasons. Some leave with command of at least elementary cognitive skills and do so because they have found desirable employment. Others leave with very weak skills and little employment prospect because they dislike school. It is not obvious that the payoff to a GED would be the same for dropouts in these two groups. The primary purpose of this paper is to show that the labor market payoffs to a GED are, in fact, quite different for the two groups of dropouts.

The best known paper on the labor market benefits of the GED credential was written by Cameron and Heckman (C-H) in 1993. C-H showed that males who dropped out of high school and subsequently obtained a GED did not fare as well in the labor market of the mid-1980s as did males who completed 12 years of schooling and graduated from high school with a conventional diploma. This finding is important because the percentage of young adults who obtain "high school completion" status by passing the GED examination has increased markedly over the last 30 years. Currently, one in seven young adults classified in the Census as a high school graduate holds a 
GED.

This paper uses data from the sophomore cohort of the High School and Beyond (HS\&B) data base to address three questions prompted by the $\mathrm{C}-\mathrm{H}$ results. First, is the differential between the earnings of young males with high school diplomas and those with a GED that C-H observed in National Longitudinal Survey of Youth (NLSY) data from the mid-1980s also present in HS\&B data from 1991? The answer is not obvious because changes in the economy have continued to depress the earnings of male workers with little formal education (Blackburn, Bloom, and Freeman 1990; Juhn, Murphy, and Pierce 1993; Katz and Murphy 1992). It is possible that economic changes led employers to pay less attention to differences among the credentials of workers with no postsecondary education or to pay more attention to these differences. Given the relevance of C-H's finding to the educational decisions of the large number of students who consider dropping out of high school each year, it seems important to examine whether the finding can be replicated with data from the early 1990s.

Second, on average, do males who leave high school before graduation obtain any labor market benefits from the GED credential? C-H (1993b) express ambivalence on this point, writing:

... the NLSY data strongly reject the hypothesis that GED recipients are the labor market equals of high school graduates. The same data do not reject the hypothesis that high school dropouts and GED recipients are indistinguishable. A closer look 
at the evidence indicates, however, that GED recipients lie between dropouts and graduates in their economic standing but are much closer to dropouts. ${ }^{2}$

The question is important because the GED is the one educational credential that a great many school dropouts obtain -- approximately half a million each year.

Third, are the labor market benefits of the GED different for dropouts who leave school with very weak cognitive skills than for dropouts who leave school with stronger skills? If this is the case, then past studies that have assumed constant effects of the GED across different skill-groups in the dropout population may have obscured important skillGED interactions. ${ }^{3}$ Exploring the possibility of such interactions will not only inform our general understanding of the nature of the payoffs to GED-acquisition, but will also help us to better understand the way that this credential works in the labor market.

To preview our central results, when we fit models with specifications similar to those used by $\mathrm{C}-\mathrm{H}$, our results are very close to theirs. ${ }^{4}$ On average, GED recipients do not fare as well in the labor market as conventional high school graduates. GED recipients do earn somewhat more, on average, than observationally similar dropouts without this credential, but much of the difference stems from differences in accumulated work experience. However, these average effects mask a more complicated pattern. GED-holders who had very weak cognitive skills as tenth graders earn substantially more at age 27 than low-skilled dropouts without the credential. For dropouts with stronger cognitive skills as tenth graders, acquisition of a GED is not associated with higher 
earnings at age 27 .

\section{The GED Credential}

In all 50 states, as well as in Canada, a school dropout can obtain the GED credential by achieving state-specific passing scores on a seven and one-half hour, fivepart written battery of tests assessing skills and knowledge in five areas: writing, social studies, science, reading, and mathematics. Until 1988 the format of the items on the test was exclusively multiple-choice. In that year an essay became part of the writing examination.

Much of the growth in the number of young adults obtaining a GED stems from government policy. ${ }^{5}$ The Adult Education Act of 1966 provided significant funds to states for GED preparation programs. The Welfare Reform Act of 1988 specified that women without high school diplomas who receive AFDC payments must either find employment, return to high school, or enroll in adult education programs, most of which are aimed at preparing participants for the GED examination. The 1986 amendments to the Higher Education Act specified that applicants for Pell grants to pay for postsecondary education or training must demonstrate "ability to benefit" from the financial aid. For a school dropout, obtaining a GED is the easiest way to satisfy this condition.

In general, information on who obtains a GED cannot be obtained from the most obvious sources, the U.S. Census of Population and the monthly Current Population 
Survey (CPS), because these surveys do not distinguish between the GED credential and a conventional high school diploma obtained by completing high school. However, the education supplement to the 1993 October CPS did ask respondents between the ages of 15 and 29 whether they graduated from high school by obtaining a conventional diploma or by obtaining a GED. We used this data source to estimate the percentages of 22-29 year-old males in each racial/ethnic group who were conventional high school graduates, GED-holders, and permanent dropouts. ${ }^{6}$ As indicated in Table 1A, less than half of Hispanic males aged 22-29 reported that they had obtained conventional high school diplomas, compared to slightly less than three-quarters of black males and slightly more than three-quarters of white non-Hispanic males. Almost four out of ten Hispanic males reported that they were school dropouts who had not obtained a GED, compared to approximately one in ten black males and one in ten white males. Four percent of black males and white males and seven percent of Hispanic males reported that they obtained high school graduate status by obtaining a GED. A surprising pattern is that approximately 10 percent of respondents indicated that they had "completed high school," but did not respond to a question asking whether they had done so by obtaining a GED. $^{7}$ A comparison of the number of self-reported GED recipients in this 1993 CPS with GED Testing Service figures on the number of 22-29 year old males in the U.S. who held the GED credential in 1993 suggests that more than 80 percent of the nonresponders were conventional high school graduates rather than GED recipients. ${ }^{8}$ 
Table 1B displays the median hourly earnings of groups defined by their secondary school leaving credentials. The median hourly wage of males who reported obtaining a GED was seven percent higher than that of male dropouts without a GED and ten percent lower than that of males who reported earning a conventional high school diploma. The median wage of males who reported that they were high school graduates but declined to identify whether they had obtained a GED was lower than the median wage of self-reported GED recipients. ${ }^{9}$

Why would a school dropout benefit in the labor market from obtaining a GED? First, studying for the GED examination may increase a dropout's skills. This is unlikely for most GED recipients, given that the median length of time GED examinees report preparing for the examination is only 30 hours (Baldwin, 1990). However, participants in some GED preparation programs do study for several hundred hours -- potentially long enough to increase skill levels. ${ }^{10}$ It seems likely that GED recipients who left school with very low cognitive skills would be those most likely to devote significant effort to studying for the GED examinations. Second, obtaining a GED may signal to employers that the dropout possesses desirable traits, such as mastery of basic skills or a high level of motivation (Spence, 1973). This could be particularly important for dropouts whose school records and initial labor market track record were poor. Third, acquisition of a GED may have indirect positive effects on subsequent earnings by improving access to post-secondary education and work experience, both of which result in increases in 
marketable skills. Our analytic strategy distinguishes the indirect effects of GED acquisition on subsequent earnings from the direct effect.

\section{The High School and Beyond Data Base}

In 1980, the U.S. Department of Education initiated the collection of information on the personal characteristics, family backgrounds, schooling, and cognitive skills of a stratified random sample of 14,825 sophomores in the nation's high schools. Follow-up interviews soliciting information on subsequent schooling and labor market activities were conducted in 1982, 1984, 1986, and most recently, 1992. ${ }^{11}$ Using questions asked in the follow-up interviews, it is possible to distinguish GED-holders from conventional high school graduates.

One strength of the High School and Beyond (HS\&B) data base is the availability of detailed transcript-based information on post-secondary education, investments that may be important determinants of earnings. A second is the availability of scores on cognitive tests taken by members of the sample during their sophomore year in high school. These scores provide information on skills that would be rewarded in the labor market irrespective of educational credentials (Neal and Johnson 1996). Consequently, the scores serve as critical control variables in isolating the impacts of credentials on later earnings. ${ }^{12}$ These scores also enable us to explore whether GED acquisition affects earnings at age 27 differently for males who had very low test scores as tenth graders than 
for males with higher tenth-grade test scores. For reasons we explain in a later section, we defined dropouts with very low cognitive skills as those whose tenth grade math scores were in the bottom quartile of the distribution of scores for high school sophomores in 1980.

The data set also contains scores on cognitive tests taken by the HS\&B sample in 1982, the high school graduation year for those members of the sample who stayed in school. As explained below, the two sets of test scores provide a basis for examining the relative achievement gains between 1980 and 1982 for students who stayed in school, for those who dropped out and obtained a GED during this period, and for those who dropped out and did not obtain the alternative credential.

One limitation of the HS\&B data is the lack of information on labor supply and hourly wages in 1990 and 1991, the two years immediately prior to the most recent interview. Only information on annual earnings is available for these years, and consequently it is not possible to determine the extent to which differences between the earnings of groups with different educational credentials stem from differences in wages versus differences in labor supply. A second limitation, particularly relevant in studying school dropouts, is that only individuals who were high school sophomores in 1980 were included in the sample. Consequently, males who had dropped out of school prior to their sophomore year are omitted.

We included in our analytic sample the 4,216 males who took the mathematics test 
administered to tenth graders in the baseline sample in 1980, participated in the 1992 survey, had positive annual earnings in 1990 or 1991, and were not in college in both of these years. For individuals who reported their earnings for both 1990 and 1991 and were not in college in either year, our dependent variable is the natural logarithm of average earnings (in 1991 dollars) over the two years. For individuals who reported positive earnings for one year and were in college during the other year or did not report earnings for the other year, we used the log of earnings for one year. We excluded all individuals who reported being in the military in 1992.

We defined our dependent variable in this manner for two reasons. First, for HS\&B participants who reported earnings for both years, the two-year average is a more precise measure of permanent income than the earnings measured in a single year. Second, using earnings (in 1991 \$) for one year for those individuals who were in college or in the military in the other year or who did not respond to the question about earnings in the other year allowed us to include 107 males who otherwise would have been omitted from the sample. Their inclusion is likely to reduce sample selection bias. Our regression models identified individuals who had earnings for one of the two years, but not both, using a pair of dichotomous predictors. ${ }^{13}$

Forty-six percent of the school dropouts in the HS\&B sample obtained a GED before 1990, the start of the two-year period for which earnings were measured. This is higher than the 35 percent of male dropouts in the NLSY sample who obtained a GED 
(Murnane, Willett, and Boudett, 1995). The explanation lies in part in differences in the sample structure. To be included in the HS\&B sophomore sample, an adolescent had to be in grade 10 in 1980, and consequently all school dropouts in the HS\&B sophomore sample completed at least nine years of schooling. The NLSY sample includes individuals who had completed as few as six years of schooling before dropping out. Among male school dropouts in the four youngest cohorts of the NLSY, forty percent of those who dropped out after completing at least nine years of schooling subsequently obtained a GED. The comparable figure for males who dropped out before completing nine years of schooling is 30 percent. $^{14}$

Table 2 summarizes the characteristics of the high school graduates, GEDrecipients, and permanent school dropouts in our sample. Overall, 10 percent of the sample is Black, 21 percent is Hispanic, 65 percent is non-Hispanic white, and 4 percent is "other"(a combination of Asians, Pacific islanders, native Americans, and otherwise not classified racial/ethnic groups). This racial/ethnic composition reflects the oversampling of Hispanic youth in the HS\&B sampling design. On average, GED recipients in this sample completed 10.3 years of schooling before dropping out. This is only slightly more than the 10.2 years of schooling completed, on average, by males who dropped out of high school and had not obtained a GED by the start of $1990 .{ }^{15}$ For ease of exposition we refer to this group as "permanent dropouts," recognizing that individuals in this group may have obtained a GED after December $31,1989 .{ }^{16}$ As illustrated by 
mother's educational attainments, GED recipients tend to come from more advantaged families than permanent dropouts, but from less advantaged families than high school graduates. A similar pattern holds for high school test scores. The average score of GED recipients on the mathematics test administered in the sophomore year was 8.6, almost twice the average score of permanent dropouts (4.5), but only slightly more than half of the average score of males who subsequently obtained a conventional high school diploma (15.3). Table 2 also shows that 18 percent of high school graduates, 38 percent of GED recipients, and 59 percent of permanent dropouts had sophomore math scores in the bottom quarter of the distribution. ${ }^{17}$

One striking characteristic of the GED recipients in the HS\&B sample is how many obtained this credential soon after leaving high school. As indicated in column 3 of Table 3, 30 percent of the recipients obtained the GED by the end of May 1982, the month when their cohort graduated from high school. Another 17 percent obtained a GED within the subsequent seven months. This concentration of the timing of GED acquisition is to some extent a result of survey design: individuals not included in the HS\&B sophomore cohort because they dropped out of school before grade 10 may have been more likely to obtain a GED later in their lives than members of the HS\&B sample; also, school dropouts in the HS\&B sample who acquired a GED after 1989 are counted as permanent dropouts. A comparison of the entries in columns 1 and 2 of Table 3 indicate that not only are dropouts who leave school with relatively strong cognitive skills more 
likely to obtain a GED than those who leave with weaker skills; they are also more likely to obtain the credential quickly. Fifty six percent of male dropouts whose tenth grade math scores were in the upper three-quarters of the test score distribution had obtained a GED by 1989, and among those who did, 37 percent obtained the credential by June 1982, the month when their high school cohort graduated. In contrast, 36 percent of male dropouts whose tenth grade math score were in the lowest quartile of the test score distribution obtained a GED by 1989, and among those who did, 19 percent obtained it by June 1982 .

The high percentage of GED recipients who obtained the credential before the end of the calendar year in which their cohort graduated from high school raises the question of whether the option of obtaining a GED very soon after leaving high school induces some students to leave school. ${ }^{18}$ There is no way to answer this question with these data. However, the question is important in light of the differences between the average earnings of conventional high school graduates and those of GED recipients that we report later in the paper.

Table 4 provides descriptive statistics on the amounts of post-secondary education obtained by conventional high school graduates, GED recipients, and permanent dropouts in the sample. All of these statistics are derived from transcript data. ${ }^{19}$ We base estimates of the number of years of post-secondary education completed on the assumption that 24 credits (eight three-credit courses) constitute a year of post-secondary education. 
Thirty percent of GED recipients obtained at least one post-secondary education credit by the end of 1990. This figure is markedly higher than the eight percent of permanent dropouts who obtained some post-secondary education, but much lower than the 69 percent of conventional high school graduates who did so. Eight percent of GED recipients completed at least two years of post-secondary education by 1990 , and less than two percent completed at least four years. Among GED recipients who did obtain post-secondary education, most did so at community colleges. Almost one in four GED recipients ( 24 percent) obtained at least one college credit in a two-year college. In contrast, only 6 percent earned a credit at a four-year college.

According to the transcript data, improved access to post-secondary education was not likely to be the mechanism through which most dropouts benefitted from obtaining a GED. The modest educational attainments of GED recipients stand in stark contrast to the responses of a national sample of GED test-takers asked about their future plans. In 1994, 66 percent responded that they were planning future study (GED Testing Service, 1995, p. 25). Part of the explanation for the difference between educational plans and the transcript-based estimates of educational attainments may be that GED recipients enrolled in institutions such as proprietary training schools that did not provide transcripts. ${ }^{20}$

\section{Data Analyses}

\section{Statistical Models}


We explored the impact of educational credentials on subsequent earnings by fitting two sets of regression models. The first set follows the assumption implicit in past GED studies and posits that the relationships between educational credentials and subsequent earnings do not depend on the skills with which students left school. Equation 1 depicts the basic model:

$$
\begin{aligned}
& y_{i}=\beta_{0}+\operatorname{yrsed}_{i} \boldsymbol{\beta}_{1}+G E D_{i}+H S G_{i}+\text { MATH }_{i}+ \\
& \operatorname{race}_{i} \beta_{2}+\operatorname{region}_{i} \beta_{3}+\operatorname{fambg}_{i} \beta_{4}+\text { yrpse }_{i}+\text { wrkexp }_{i}+\operatorname{miss} 9091_{i} \beta_{5}+{ }_{1 i}
\end{aligned}
$$

where:

$\mathrm{y}_{\mathrm{i}}=$ natural log of the average of 1990 and 1991 annual earnings, $\boldsymbol{y r s e d}_{i}=$ a vector of two dummy variables indicating whether individual $i$ finished the 10th or the 11th grade before dropping out (finishing the 9th grade is the omitted category),

$G E D_{i}=1$ if individual $i$ has a GED, 0 otherwise, $H S G_{i}=1$ if individual $i$ is a regular high school graduate, $M A_{H}=$ individual $i$ 's score on the sophomore math test, race $_{i}=$ a vector of dummy variables indicating whether individual $i$ is black, Hispanic, or in the "other" race category ("white" is the omitted category), region $_{i}=$ a vector of three dummy variables indicating the region of the country in which individual $i$ 's school was located during the sophomore year in high school, 
$\operatorname{fambg}_{i}=\mathrm{a}$ two element vector of family background variables that include the highest level of education of individual $i$ 's mother and the number of siblings in individuals $i$ 's family when a sophomore, ${ }_{y r p s} e_{i}=$ the number of years of post-secondary education attained by individual $i$ as measured by transcript data, $\boldsymbol{w r k e x p}_{i}=$ a two element vector of work experience that includes actual work experience and work experience squared, miss9091 $=$ two dummy variables indicating whether or not the individual had missing earnings in either 1990 or 1991 , $\epsilon_{l i}=$ a normally distributed, mean zero error term, and the $\beta$ 's, $\alpha, \gamma, \delta, \zeta$, and $\theta$ 's are parameters to be estimated.

The second set of regression models allows the relationships between educational credentials and subsequent earnings to differ by tenth grade math score. Equation 2 depicts the basic model:

$$
\begin{aligned}
& y_{i}=\beta_{0}+\operatorname{yrsed}_{i} \beta_{1}+G E D_{i}+H S G_{i}+ \\
& \text { math }_{i}+\left(G E D \text { math }_{i}+(H S G \text { math })_{i}+\right. \\
& \operatorname{race}_{i} \beta_{2}+\operatorname{region}_{i} \beta_{3}+\operatorname{fambg}_{i} \beta_{4}+\text { yrpse }_{i}+\operatorname{wrkexp}_{i}+\operatorname{miss} 9091_{i} \beta_{5}+{ }_{2 i}
\end{aligned}
$$

where, $\boldsymbol{m a t h}_{i}=$ a vector of three dummy variables indicating whether or not individual $i$ was in 
math quartile 2,3 , or 4 (quartile 1 is the omitted category),

$\left(G E D_{i}^{*} \boldsymbol{m a t h}\right)=$ a three element vector where GED is interacted with the three math quartile dummies, $\left(H S G_{i}^{*} \boldsymbol{m a t h}\right)=$ a three element vector where $H S G$ is interacted with the three math quartile dummies, $\epsilon_{2 i}=$ a normally distributed, mean zero error term, and the $\beta^{*}$ 's, $\alpha^{*}, \gamma^{*}, \lambda$ 's, $\kappa^{\prime}$ 's, $\xi^{\prime}$ s, $\zeta^{*}$, and $\theta^{*}$ 's are parameters to be estimated.

\section{Estimation}

We fitted our models using standard regression methods, computing standard errors by robust methods that do not depend on normality assumptions (White, 1980). We did not use the sample weights in fitting our models because the analytic sample was a non-random subset of the full sample and included only members of the HS\&B sophomore cohort who took the tenth grade math test and who reported earnings for 1990 or 1991. Consequently, application of the sample weights would not have created a sample representative of males who were in $10^{\text {th }}$ grade in 1980. Since the original HS\&B design did oversample particular groups, especially Hispanic students, the decision to weight each observation equally gives disproportionate weight to these groups. As explained below, we verified that our substantive results are not sensitive to the decision on whether to use the sampling weights. 


\section{The Effects of Education Credentials on Earnings}

\section{Treating GED recipients as a single group}

Table 5 presents parameter estimates and associated standard errors for a set of fitted models similar to Equation 1, predicting the impact of educational credentials on the natural log of average annual earnings, controlling for race and ethnicity, tenth grade math score ${ }^{21}$ region, and a set of family background characteristics. The omitted category for the years of secondary school completed is grade 9. The models reported in Table 5 are similar to those fitted by C-H. Most importantly, they do not distinguish between GED effects for dropouts who left school with very weak cognitive skills and for those who left with somewhat stronger skills.

The coefficient on the dichotomous variable representing high school graduate in Models 1 through 3 is an estimate of the average difference between the log earnings of male high school graduates and those of observationally similar males who dropped out of school after completing grade nine (Model 1), holding constant years of work experience (Model 2), and holding constant both work experience and years of postsecondary education (Model 3). The coefficients on the GED indicator in Models 1-3 can be interpreted similarly as estimates of the difference in log earnings between a GED recipient and a permanent dropout with the same number of years of completed schooling. 
The estimated coefficient on high school graduate in Model 1 of Table 5 implies that high school graduates with no post-secondary education earned 42 percent more than observationally comparable permanent dropouts who completed nine years of schooling, and 32 percent more than permanent dropouts who left school after completing 11 years of schooling. ${ }^{22}$ On average, GED recipients earned 13 percent more than permanent dropouts without this credential who had completed the same number of years of high school. ${ }^{23}$

Cameron \& Heckman (1993b) report that the estimated wage differentials between conventional high school graduates, GED recipients, and permanent dropouts are smaller in models that control for work experience than in models that do not. We find the same pattern for the earnings differentials in our data. The estimate of the earnings differential between conventional high school graduates and permanent dropouts is approximately one-quarter smaller in Model 2, which controls for years of work experience, than in Model 1, which does not. Similarly, the estimate of the earnings differential between GED recipients and permanent dropouts is smaller by one-third in the model that controls for work experience than in the model that does not. The explanation is that years of work experience has a strong positive relationship with log earnings, and high school graduates have more work experience by age 27 than do GED recipients, who in turn have more work experience than permanent dropouts. ${ }^{24}$

The coefficient on high school graduate in Model 3, which controls for years of 
completed post-secondary education, is 17 percent lower than the analogous coefficient in Model 2, which does not control for post-secondary education. The explanation is straightforward. High school graduates complete more years of post-secondary education than do school dropouts, and each year of completed college is associated with a four percent increase in earnings at age 27 . In other words, access to college is a primary mechanism through which the conventional high school diploma results in higher earnings at age 27 .

The coefficients on GED are virtually identical in Column 2 and Column 3. The explanation is not that post-secondary education does not pay off for GED recipients. In fact, college pays off as well for GED recipients as it does for conventional high school graduates. ${ }^{25}$ Instead, the explanation, as shown in Table 2, is that GED recipients obtain only marginally more post-secondary education than do permanent dropouts. In fact, among dropouts with the same sophomore test scores, GED recipients obtain no more post-secondary education than permanent dropouts.

At the bottom of Table 5, for each model, we list the result of testing the hypothesis that GED recipients who dropped out after $11^{\text {th }}$ grade earn as much at age 27 as high school graduates. This null hypothesis can be rejected unequivocally in Models 1 and 2 that do not control for years of post-secondary education. However, it cannot be rejected in Model 3, which controls for post-secondary education, even though the predicted earnings differential between high school graduates and GED recipients who 
left school after completing $11^{\text {th }}$ grade is substantial in this model (nine percent). The reason the predicted high school graduate/GED earnings differential is smaller in Model 3 than in the models that do not control for post-secondary education is that one of the most powerful mechanisms through which conventional high school graduation, but not receipt of a GED, pays off is by increasing access to post-secondary education. ${ }^{26}$

The t-statistic associated with the coefficient on GED recipient in Model 1 $(\mathrm{t}=2.01)$ indicates that GED recipients do fare better, on average, in the labor market than permanent dropouts with the same sophomore test scores and years of completed secondary school. However, much of the impact consists of improved access to work. Holding constant years of work experience (Models 2 and 3), there is no statistically significant difference between the annual earnings of GED recipients, treated as a single group, and those of observationally similar permanent dropouts. In this respect our findings are similar to those of $\mathrm{C}-\mathrm{H}$.

\section{Distinguishing GED effects for Dropouts with Low Sophomore Test Scores from Those for Dropouts with Higher Sophomore Scores}

In research using different data and a different methology, we found quite large labor market benefits associated with the GED credential for dropouts whose cognitive skills were just sufficient to pass the GED exams (Tyler, Murnane, and Willett 1997). These results suggested that the common practice of treating GED recipients as a single group in studies of the labor market effects of the credential could obscure differential 
effects for different skills groups. To explore this, we recoded math test scores into quartiles, based on the distribution of math scores for the baseline HS\&B sample. We then fitted a taxonomy of regression models similar to Equation 2 that included dummy variables representing the main effects of test score quartiles, the main effects of secondary school credentials (GED and high school graduate), and the interaction of the test score quartiles with the two secondary school credentials. Parameter estimates are reported in Table 6. As in Table 5, Model 1 of Table 6 does not control for years of work experience or years of post-secondary education; Model 2 includes work experience; and Model 3 includes both work experience and years of post-secondary education.

We then tested a series of hypotheses concerning the relative value of the GED and the high school diploma for males with particular tenth grade math scores. We found striking contrasts between the results for males whose tenth grade scores were in the top three quartiles of the test score distribution and the results for males whose scores were in the lowest quartile of the distribution. We could not reject the null hypotheses that the magnitude of the GED effect was the same for males in the three top quartiles. Thus, we refer to males with scores in the top three quartiles as higher scoring males, and to males with scores in the bottom quartile as low scoring males. The results of the key hypothesis tests are reported at the bottom of Table 6 .

In models that do not control for years of completed post-secondary education (Models 1 and 2), high school graduates with tenth grade math scores in the upper three 
quartiles of the score distribution unequivocally earn more on average at age 27 than do GED recipients with similar math scores $(\mathrm{p}<.01)$. However, in models that hold constant years of completed post-secondary education (models 3,4 , and 5), we cannot reject the null hypothesis at the .10 level that earnings at age 27 do not differ between the two groups (Hypothesis 4, Table 6). The explanation lies in the importance of post-secondary education. College pays off for both high school graduates and GED recipients. However, as shown in Table 2, conventional high school graduates complete almost two and one-half more years of college, on average, than do GED recipients. Consequently, holding constant years of completed post-secondary education (Models 3, 4, and 5) eliminates a primary mechanism (college enrollment) through which high school graduates differentiate themselves from GED recipients. ${ }^{27}$ It is also the case that among higher scoring males, there is no statistically significant difference between the earnings at age 27 of permanent dropouts and those dropouts with a GED (Hypothesis 3, Table 6).

Among low scoring males the pattern is quite different. In all models low scoring GED recipients have higher predicted earnings than low scoring permanent dropouts with the same observed characteristics ( $\mathrm{p}<.01$ ). In Model 1, for instance, which does not control for work experience, the estimated earnings difference is 36 percent. $^{28}$ The estimated earnings difference is eight percentage points lower in Model 2, reflecting the importance of work experience as a mechanism through which the GED credential 
impacts on the earnings of low scoring dropouts. Adding years of post-secondary education (Model 3) does not markedly alter the estimated earnings difference, reflecting the negligible post-secondary educational attainments of low scoring GED recipients as well as low scoring permanent dropouts.

The earnings premiums of 36 percent associated with the GED for school dropouts with tenth grade test scores in the lowest quarter of the test score distribution seems high. Indeed, it is higher than the 10-19 percent estimate of a GED effect that Tyler, Murnane, and Willett (1997) obtained for white dropouts with low test scores in a study that used Social Security earnings data and a natural experiment methodology. There are two, potentially complementary reasons why the 36 percent estimate may be upwardly biased: measurement error and omitted variable bias. Some of the GED recipients with scores in the bottom quartile on the relatively short tenth grade math test may actually have had stronger cognitive skills than their low test scores indicated. These stronger skills enabled them to pass the GED exams and also were valued in the labor market. Also, those dropouts with test scores in the bottom quartile who did obtain a GED may have had unobserved strengths even as tenth graders, such as very high levels of motivation and persistence, that employers would have rewarded even had the dropouts not obtained the GED credential. ${ }^{29}$

While these potential sources of bias are certainly plausible, it is important to keep in mind that even if the true effect of GED acquisition on the earnings of males who left 
school with weak cognitive skills is half as large as the estimated impact of 36 percent, the basic story would still hold. This story is that acquisition of a GED leads to higher subsequent earnings for male dropouts who left school with very weak cognitive skills, but not for dropouts who left school with somewhat stronger skills. To understand this, it is important to keep in mind that low scoring permanent dropouts are the least attractive job candidates to most employers. It seems plausible that employers who do consider job candidates from this generally unattractive pool would favor those with the motivation to take a seven and one half hour exam and sufficient cognitive skills to pass the five parts of the exam. Much of the earnings differential between GED recipients with low sophomore test scores and observationally similar permanent dropouts may stem from the credential improving access to work.

Another way to view the evidence is that the earnings at age 27 of dropouts who had very low test scores as sophomores and subsequently earned a GED are about the same as those of permanent dropouts whose tenth grade math scores were in the upper three quarters of the test score distribution. This pattern raises the following questions: Given that permanent dropouts with relatively high tenth grade math scores earned considerably more at age 27 than did permanent dropouts with low tenth grade math scores, doesn't this mean that employers reward the cognitive skills of dropouts without their being signaled by the GED credential? Doesn't it mean that dropouts who left school with weak cognitive skills, but subsequently increased these skills and perhaps 
improved their work ethic as well, would have been able to convince employers of their increased value without the GED credential? The HS\&B data base lacks the experimental data to address these questions. However, it seems plausible that high scoring dropouts may have been pulled into the labor market by relatively attractive job opportunities that helped them to establish a solid employment record. In contrast, the poor employment record of dropouts who left school with weak cognitive skills and a poor work ethic may have been a significant obstacle to overcome for those who subsequently acquire the skills and attitudes to be more productive employees. ${ }^{30}$ Completing and passing the lengthy battery of exams required to obtain the GED credential may have enabled dropouts who did increase their skills to signal to employers their increased value.

Among males with tenth grade math scores in the lowest quarter of the distribution, there is no statistically significant difference in earnings at age 27 between those who graduated from high school and those who dropped out after completing eleventh grade and subsequently obtained a GED (Hypothesis 2, Table 6). Both earned 45-50 percent more than permanent dropouts who dropped out before completing tenth grade and did so with tenth grade math scores in the lowest quarter of the national distribution. Again, it is important to put this pattern in perspective. The 18 percent of high school graduates who had tenth grade math scores in the lowest quarter of the test score distribution were likely to be among the least academically skilled of high school 
graduates. The results for Model 1 of Table 6 show that the labor market did not treat all 27-year-old high school graduates alike. Those with tenth grade test scores in the bottom quartile of the distribution earned approximately 25 percent less than high school graduates with higher tenth grade math scores. By passing a lengthy battery of examinations, GED recipients demonstrate that they are as productive as the least skilled high school graduates, a group earning considerably less at age 27 than high school graduates with greater tenth grade cognitive skills.

Several other parameter estimates in the fitted models displayed in Table 6 are notable. Controlling for years of completed work experience, each year of completed post-secondary education increases subsequent earnings by an estimated four percent (Model 3), a return similar to that reported by Kane \& Rouse (1995). ${ }^{31}$ As mentioned above, we found no evidence that the earnings premium from post-secondary education was different for GED-holders than for conventional high school graduates.

One other striking pattern in Table 6 is that the magnitude of the Black-White earnings differential is considerably smaller in Model 2, which include controls for years of work experience, than in Model 1, which does not. The explanation is that Black males have, on average, almost one year less work experience as of age 27 than do White males, and work experience is a critical determinant of earnings.

\section{Sensitivity analyses}


We conducted a variety of sensitivity analyses to examine the robustness of our results. Model 4 of Table 6 presents the estimated coefficients of a model identical to Model 3 except the dummy variables indicating that information on earnings was missing for either 1990 or 1991 are omitted. Model 5 differs from Model 3 only in that it includes as additional control variables tenth grade scores on tests of reading, science. The estimated coefficients in Model 4 and Model 5 are very similar to those in Model 3, and there are no differences in the results of the critical hypothesis tests.

We also fitted a variety of models with different parameterizations of the interactions between sophomore math score and the GED and high school diploma. ${ }^{32}$ The results were consistent: among dropouts with low tenth grade math scores, those who subsequently obtained a GED earned more at age 27 than those who did not obtain this credential. Dropouts who had higher tenth grade math scores earned more at age 27 than observationally similar dropouts with low tenth grade scores. Among higher scoring dropouts, those with a GED did not earn more at age 27 than those without this credential.

\section{Sample selection bias}

Interpreting the critical coefficients in Model 3 of Table 6 as the direct effects of educational credentials on earnings rests on the assumption that, after conditioning on observable individual characteristics, the 4,216 males for whom we observe earnings and 
tenth grade test scores are a random subsample of the males in the HS\&B data set. As the extensive literature on selection bias documents, this assumption may not be valid. As a result, relationships between educational credentials and subsequent earnings in the selfselected sample may not provide unbiased estimates of the relationships in the population of males who were high school sophomores in 1980.

Two hundred seventy eight males were excluded from our earnings sample because they were in college in both of the years in which we measured earnings, 166 because they were not working and were not in college during these years, and 683 because they did not complete the tenth grade math test administered in 1980 . C-H (1993b) attempted to deal with the sample selection problem by fitting a wage equation that included as predictors two inverse Mills ratios, from bivariate probit selection equations describing an individual's "risk" of being in the earnings sample given that he is (1) working and (2) not in college. In the models that included the selection terms, the coefficients indicating the earnings premiums high school graduates and GED recipients received relative to the earnings of permanent dropouts were 10-50 percent smaller than the analogous premiums estimated in models without the selection terms.

C-H (1993b) do not emphasize the extent to which their results are sensitive to the corrections for selectivity bias. One reason may be that they did not have confidence in the exclusion restrictions that they used for identification -- namely, that indicators of local labor market conditions belong in the probit equations, but do not belong in the 
main wage equation. ${ }^{33}$

Had we been able to identify appropriate exclusion restrictions, we would have fitted selection models analogous to those employed by C-H. However, our data set did not include any variables that we could use for defensible exclusion restrictions. ${ }^{34}$ As mentioned above, our central results would not change if the critical coefficients were 10-50 percent smaller. It would still be the case that acquisition of a GED is associated with considerably higher earnings for male dropouts who left school with very low cognitive skills, but not for dropouts who left school with higher skills.

\section{Does preparation for the GED exams result in an increase in cognitive skills?}

While the self-reports of GED test-takers indicate that most do not spend a great deal of time studying for the exams, some do. This led us to wonder whether the cognitive skills of dropouts who passed the GED exams increased more between 1980 and 1982 than did the skills of permanent dropouts, and whether they increased as much as the skills of their peers who graduated from high school in 1982. To examine this question, we fitted models in which the gains in score between 1980 and 1982 on tests of

reading, writing, science, and mathematics were the dependent variables. ${ }^{35}$ Explanatory variables included the number of years of high school completed, and two dichotomous variables, one indicating that the individual obtained a GED between 1980 and 1982, and the second indicating that the individual obtained a GED between 1983 and 1989. The 
reason for two indicators of receipt of GED is that it seemed likely that dropouts who passed the GED exams between 1980 and 1982 would be more likely to show gains in cognitive skills between 1980 and 1982 than would be the case for dropouts who passed the GED exams after 1982, since test preparation by the early GED recipients may have increased the cognitive skills that are measured by the 1982 High School and Beyond standardized tests. All models also included controls for race and ethnicity, family background characteristics, and scores on the other tenth grade tests.

The models predicting the test score gains between 1980 and 1982 have little statistical power. However, the estimated coefficients, which are displayed in Table 7, show several consistent patterns. Students who graduated from high school increased their skills in each subject area between 1980 and 1982 more than did permanent dropouts. The point estimates imply that dropouts who obtained a GED also increased their skills in all subject areas more than did permanent dropouts with the same number of years of completed high school. Moreover, those dropouts who obtained the GED credential between 1980 and 1982 increased their cognitive skills during this period more than did dropouts who obtained a GED at a later date. While it is not possible to eliminate the possibility that this pattern reflects unobserved heterogeneity, the pattern is consistent with the hypothesis that studying for the GED examination did increase the math skills of dropouts. 


\section{Conclusion}

In models that treat GED recipients as a single group, the results of our analyses using HS\&B data support Cameron \& Heckman's (1993b) primary conclusion: male GED recipients did not earn as much in the early 1990s at age 27 as did conventional high school graduates, even after taking into account that they come from less advantaged families and had lower academic skill levels when they were sophomores in high school. On average, GED recipients earned somewhat more at age 27 than observationally similar permanent dropouts, but the difference is statistically significant only in models that do not control for years of work experience.

The most important new insight from this paper is that the average difference between the earnings of GED recipients treated as a single group and those of permanent dropouts reflects quite a large difference for dropouts who leave school with very weak cognitive skills and no difference for dropouts who leave school with somewhat higher skills. The logic underlying this pattern is that dropouts who left school with very weak academic skills are the least desirable applicants for most jobs. As a result they earn only about two-thirds as much at age 27 as dropouts who left school with stronger academic skills. Those dropouts with low sophomore test scores who later increase their skills and perhaps improve their work ethic as well appear to use the GED to signal to employers that they are more desirable employees than they had been in the past. This signal enables them to increase their earnings to the level of permanent dropouts and 
GED recipients who left school with stronger cognitive skills. This earnings level is considerably higher than the earnings of permanent dropouts with the same low tenth grade skills.

Post-secondary education pays off for GED-holders as well as for high school graduates. Consequently, those GED recipients who use the credential to gain access to post-secondary education benefit from this investment. However, only 11 percent of GED-holders had completed at least one year of college by the age of 27 , and only 8 percent had completed at least two years of college.

In summary, the evidence for males from High School and Beyond indicates that labor market benefits in the early 1990s associated with a GED accrued primarily to the subset of dropouts who left school with very low academic skills.

A potential cost of the GED certification program is that its existence may induce some high school students who do have the cognitive skills to obtain a conventional high school diploma to drop out of school and acquire the alternative credential. The evidence from High School \& Beyond is that the GED credential is the labor market equivalent of a high school diploma only for males who had extremely low academic skills as tenth graders. These males, both those with a high school diploma and those with a GED, fare poorly in the labor market. For males with tenth grade academic skills in the upper three quarters of the test score distribution, the GED is not the labor market equivalent of the conventional high school diploma. 
Table 1A. Distribution of educational credentials by race/ethnicity for males age 22-29 in the October 1993 Current Population Survey. (Estimates obtained using sample weights.)

\begin{tabular}{llccc}
\hline & \multicolumn{4}{c}{ Distribution of Educational Credentials by Race } \\
\cline { 2 - 5 } Credential & White & Black & Hispanic & Other \\
\hline Number of observations & 4847 & 606 & 653 & 285 \\
& & & & \\
$\begin{array}{l}\text { Conventional HS } \\
\text { graduates }\end{array}$ & 0.78 & 0.72 & 0.48 & 0.79 \\
& & & & \\
GED holder & 0.04 & 0.04 & 0.07 & 0.04 \\
$\begin{array}{l}\text { Permanent dropouts } \\
\text { Did not respond to query }\end{array}$ & 0.08 & 0.11 & 0.37 & 0.07 \\
$\begin{array}{l}\text { as to how HS graduate } \\
\text { status was obtained }\end{array}$ & 0.10 & 0.12 & 0.08 & 0.10 \\
\hline \hline
\end{tabular}

Table 1B. Median hourly wages of males age 22-29 in the outgoing rotation group of the October 1993 Current Population Survey. (Estimates obtained using sample weights.)

\begin{tabular}{lcccc} 
& \multicolumn{4}{c}{ Secondary School Educational Credential } \\
\cline { 2 - 5 } & $\begin{array}{c}\text { Permanent } \\
\text { Dropout }\end{array}$ & $\begin{array}{c}\text { GED- } \\
\text { holder }\end{array}$ & $\begin{array}{c}\text { Conventional } \\
\text { HS graduates }\end{array}$ & $\begin{array}{c}\text { Did not } \\
\text { respond }\end{array}$ \\
\hline $\begin{array}{l}\text { Number of } \\
\text { observations* }\end{array}$ & 133 & 48 & 701 & 95 \\
$\begin{array}{l}\text { Median hourly } \\
\text { wages }\end{array}$ & 6.80 & 7.25 & 8.02 & 7.00 \\
\hline \hline
\end{tabular}

* Sample sizes in Table 1B are smaller than those in Table 1A because only members of the outgoing rotation groups reported hourly wages. 
Table 2. Descriptive statistics of the analytic sample of 4,216 males from the High School and Beyond data set. (Estimates obtained without using sample weights, standard deviations in parentheses.)

\begin{tabular}{lcccc}
\hline & $\begin{array}{c}\text { Conventional } \\
\text { HS graduates }\end{array}$ & $\begin{array}{c}\text { GED- } \\
\text { holders }\end{array}$ & $\begin{array}{c}\text { Permanent } \\
\text { dropouts }\end{array}$ & All \\
\hline Number of observations & 3663 & 255 & 298 & 4216 \\
Mean... & & & & \\
log avg. 1990 and 1991 earnings & 10.01 & 9.77 & 9.58 & 9.97 \\
& $(0.62)$ & $(0.65)$ & $(0.85)$ & $(0.65)$ \\
average 1990 and 1991 earnings & & & & \\
& 25776 & 20553 & 18440 & 24941 \\
& $(12772)$ & $(10669)$ & $(11002)$ & $(12723)$ \\
years of post secondary education & & & & 2.50 \\
years of completed schooling, mother & $(2.85$ & 0.41 & 0.06 & $(2.86)$ \\
& 12.82 & $(1.04)$ & $(0.36)$ & 12.69 \\
number of siblings when a sophomore & $(2.18)$ & $(2.00)$ & $(1.66)$ & $(2.17)$ \\
& 2.85 & 3.43 & 3.74 & 2.94 \\
years of work experience & $(1.74)$ & $(1.98)$ & $(1.98)$ & $(1.79)$ \\
& & & & \\
sophomore math test score & 8.16 & 8.08 & 7.90 & 8.14 \\
& $(1.60)$ & $(1.54)$ & $(1.89)$ & $(1.62)$ \\
& 15.25 & 8.64 & 4.51 & 14.09 \\
& $(9.99)$ & $(7.96)$ & $(6.61)$ & $(10.16)$
\end{tabular}

Fraction...

who completed grade 10

who completed grade 11

who completed grade 12

white

black

Hispanic

in other race category

in the low math category

in the high math category

missing 1990 earnings
0

0

1.00

0.65

0.11

0.20

0.04

0.18

0.82

0.08
0.40

0.45

0.00

0.66

0.09

0.20

0.04

0.38

0.62

0.05
0.38

0.43

0.00

0.61

0.07

0.27

0.05

0.59

0.41

0.06
0.05

0.06

0.87

0.65

0.10

0.21

0.04

0.22

0.78

0.08 
missing 1991 earnings

in the 1st math quartile

in the 2 nd math quartile

in the 3rd math quartile

in the 4th math quartile
0.03

0.18

0.22

0.27

0.34
0.06

0.04

0.59

0.28

0.09

0.25

0.08

0.38

0.29

0.04
0.04

0.22

0.23

0.25

$=$ 
Table 3. Timing of GED acquisition for dropouts in the analytic sample who obtained a GED by the end of 1989. (Estimates obtained without using sample weights.)

\begin{tabular}{lccc}
\hline & $\begin{array}{c}\text { GED-holders } \\
\text { in the low math } \\
\text { category }\end{array}$ & $\begin{array}{c}\text { GED-holders } \\
\text { in the high } \\
\text { math category }\end{array}$ & $\begin{array}{c}\text { All } \\
\text { GED-holders }\end{array}$ \\
\hline $\begin{array}{l}\text { Number of observations } \\
\text { Fraction who obtained their GED... }\end{array}$ & 97 & 158 & 255 \\
$\quad$ before June 1982 & 0.19 & 0.37 & 0.30 \\
$\quad$ between June 1982 and Dec. 1982 & 0.19 & 0.16 & 0.17 \\
$\quad$ in 1983 or 1984 & 0.40 & 0.27 & 0.32 \\
$\quad$ in 1985 or 1986 & 0.09 & 0.09 & 0.09 \\
$\quad$ from 1987 through 1989 & 0.13 & 0.10 & 0.11 \\
$\begin{array}{l}\text { Percentage of dropouts by math } \\
\text { category who obtained a GED by } \\
1989\end{array}$ & 0.36 & & 0.46 \\
\hline \hline
\end{tabular}


Table 4. Amounts and types of post-secondary education by educational credential for the analytic sample of 4,216 males in the High School and Beyond data set.

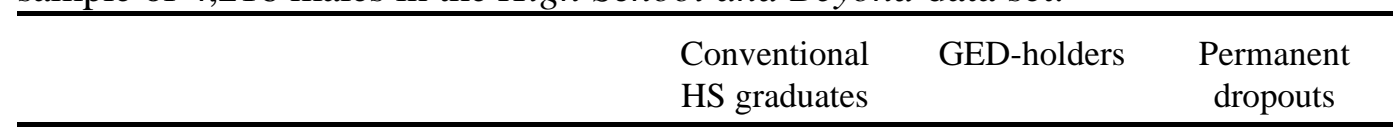

Panel A.

Fraction with...

$\begin{array}{lllc}\text { zero years of post-secondary } & 0.31 & 0.70 & 0.92 \\ 0<\text { years }<1 \text { of post-secondary } & 0.11 & 0.19 & 0.06 \\ 1<=\text { years }<2 \text { of post-secondary } & 0.09 & 0.03 & 0.01 \\ 2<=\text { years }<3 \text { of post-secondary } & 0.07 & 0.04 & 0 \\ 3<=\text { years }<4 \text { of post-secondary } & 0.06 & 0.03 & 0.003 \\ 4 \text { or more years of post-secondary } & 0.36 & 0.01 & 0.003\end{array}$

Panel B.

$\begin{array}{llll}\text { Mean years of post-secondary } & 2.85 & 0.41 & 0.07\end{array}$

(2.90) (1.04) $\quad(0.36)$

Panel C.

Fraction with at least 1 credit in...
a 4-year college
0.48
0.06
0.01
a 2-year college
0.32
0.24
0.06
a non-college training program
0.04
0.04
0.01

Note that the definitions in Panel A are mutually exclusive and, hence, the entries in a column sum to 1 . The definitions in Panel C, however, are not mutually exclusive (e.g., an individual could have earned credits in both a two-year and a four-year institution). Hence, we would expect the sum of the entries in a column to be higher than the estimate of the percentage of a group who obtained at least one post-secondary credit. 
Table 5. Estimates from regressions of log average 1990-1991 earnings in models that assume a constant "GED effect" across math scores. (standard errors in parentheses, $* *=$ significant at the 0.01 level, $*=$ significant at the 0.05 level)

\begin{tabular}{llll}
\hline & Model 1 & Model 2 & Model 3 \\
\hline Intrcpt & $9.480^{* *}$ & $7.810^{* *}$ & $7.833^{* *}$ \\
& $(0.116)$ & $(0.260)$ & $(0.253)$
\end{tabular}

Race

Black

Hispanic

Other

Educ.

10th grade

11th grade

GED

HS graduate

Math

10th grade.

.

Hraduate

$\begin{array}{lrr}-0.132 * * & -0.071 & -0.068 \\ (0.039) & (0.037) & (0.036) \\ -0.055^{*} & -0.039 & -0.040 \\ (0.026) & (0.025) & (0.025) \\ -0.074 & 0.024 & 0.015\end{array}$

Linear math

Indirect mech.

Work exp.

$(\text { Work exp. })^{2}$

Years of Post-Sec. Ed.

$$
\begin{array}{lll}
0.011 * * & 0.012 * * & 0.008^{* *} \\
(0.001) & (0.001) & (0.001)
\end{array}
$$

$\begin{array}{lll}(0.096) & (0.083) \quad(0.083)\end{array}$




\begin{tabular}{|c|c|c|c|}
\hline Missing earnings dummies & Yes & Yes & Yes \\
\hline $\mathrm{R}^{2}$ & 0.094 & 0.154 & 0.168 \\
\hline $\begin{array}{l}\mathrm{H}_{0} 1 \text { : } \\
\text { Pr. p>F }\end{array}$ & 0.004 & 0.009 & 0.101 \\
\hline
\end{tabular}

Null \#1: The log earnings of GED-holders with 11 years of completed schooling equals the log earnings of high school graduates. 
Table 6. Estimates from regressions of log average 1990-1991 earnings in models that allow the effect of the GED on log earnings to vary across math score octiles. (standard errors in parentheses, $* *=$ significant at the 0.01 level, $*=$ significant at the 0.05 level)

\begin{tabular}{lcccccc}
\hline & Model 1 & Model 2 & Model 3 & Model 4 & Model 5 \\
\hline Intrcpt & $9.390^{* *}$ & $7.779 * *$ & $7.791 * *$ & $7.697 * *$ & $7.747 * *$ \\
& $(0.125)$ & $(0.264)$ & $(0.255)$ & $(0.250)$ & $(0.264)$
\end{tabular}

Race

\begin{tabular}{lccccc} 
Black & $-0.133^{* *}$ & $-0.076^{*}$ & $-0.072^{*}$ & $-0.076^{*}$ & -0.070 \\
& $(0.039)$ & $(0.037)$ & $(0.036)$ & $(0.037)$ & $(0.037)$ \\
Hispanic & $-0.057^{*}$ & -0.041 & -0.042 & -0.049 & -0.043 \\
& $(0.026)$ & $(0.025)$ & $(0.025)$ & $(0.025)$ & $(0.025)$ \\
\multirow{2}{*}{ Other } & & & & \\
& -0.069 & 0.028 & 0.017 & 0.009 & 0.008 \\
& $(0.056)$ & $(0.052)$ & $(0.050)$ & $(0.050)$ & $(0.052)$
\end{tabular}

Education

$\begin{array}{lccccc}\text { 10th grade } & 0.051 & 0.035 & 0.034 & 0.039 & 0.020 \\ & (0.103) & (0.093) & (0.092) & (0.093) & (0.094) \\ \text { 11th grade } & & & & & \\ & 0.075 & 0.062 & 0.054 & 0.059 & 0.047 \\ \text { GED } & (0.098) & (0.088) & (0.087) & (0.088) & (0.090) \\ & 0.306^{* *} & 0.247^{*} & 0.242^{*} & 0.236^{*} & 0.243 \\ \text { HS graduate } & (0.097) & (0.090) & (0.089) & (0.091) & (0.093) \\ & 0.414^{* *} & 0.320^{* *} & 0.286^{* *} & 0.296^{* *} & 0.275^{* *} \\ & (0.112) & (0.098) & (0.097) & (0.098) & (0.101)\end{array}$

Math

$$
\begin{array}{cccccc}
2^{\text {nd }} \text { quartile } & 0.326 * * & 0.242 * * & 0.234 * * & 0.241^{* *} & 0.223 * \\
& (0.095) & (0.098) & (0.088) & (0.090) & (0.123) \\
3^{\text {rd }} \text { quartile } & 0.275 & 0.250 & 0.266 & 0.254 & 0.253 \\
& (0.187) & (0.181) & (0.180) & (0.180) & (0.179) \\
& & & & & \\
4^{\text {th }} \text { quartile } & 0.433^{* *} & 0.411^{* *} & 0.406 * * & 0.411 * * & 0.383 * \\
& (0.156) & (0.148) & (0.144) & (0.153) & (0.150)
\end{array}
$$

Math X Educ.

Interactions

GED X math

$\begin{array}{lccccc}\text { GED X } & -0.394 * * & -0.306^{*} & -0.303^{*} & -0.302^{*} & -0.300^{*} \\ 2^{\text {nd }} \text { quartile } & (0.142) & (0.135) & (0.134) & (0.135) & (0.137) \\ \text { GED X } & -0.250 & -0.243 & -0.271 & -0.259 & -0.285 \\ 3^{\text {rd }} \text { quartile } & (0.214) & (0.206) & (0.205) & (0.205) & (0.207)\end{array}$




$\begin{array}{llllll}\text { GED X } & -0.314 & -0.316 & -0.340 & -0.352 & -0.350 \\ 4^{\text {th }} \text { quartile } & (0.193) & (0.191) & (0.186) & (0.194) & (0.190)\end{array}$

HSgradXmath

$\begin{array}{lccccc}\text { HSG X } & -0.199 * & -0.119 & -0.142 & -0.153 & -0.141 \\ 2^{\text {nd }} \text { quartile } & (0.101) & (0.094) & (0.094) & (0.096) & (0.096) \\ & & & & & \\ \text { HSG X } & -0.072 & -0.051 & -0.141 & -0.131 & -0.144 \\ 3^{\text {rd }} \text { quartile } & (0.190) & (0.184) & (0.183) & (0.183) & (0.183) \\ & & & & & \\ \text { HSG X } & -0.158 & -0.104 & -0.217 & -0.226 & -0.217 \\ 4^{\text {th }} \text { quartile } & (0.158) & (0.151) & (0.148) & (0.156) & (0.150)\end{array}$

Indirect mech.

Work exp.

$(\text { Work exp. })^{2}$

PSE

$$
\begin{array}{cccc}
0.341 * * & 0.340 * * & 0.358 * * & 0.345 * * \\
(0.061) & (0.059) & (0.058) & (0.060) \\
-0.017 * * & -0.016 * * & -0.017 * * & -0.016 * * \\
(0.004) & (0.004) & (0.004) & (0.004) \\
& & & \\
& 0.038 * * & 0.035 * * & 0.036 * \\
& (0.005) & (0.005) & (0.005)
\end{array}
$$

Other controls

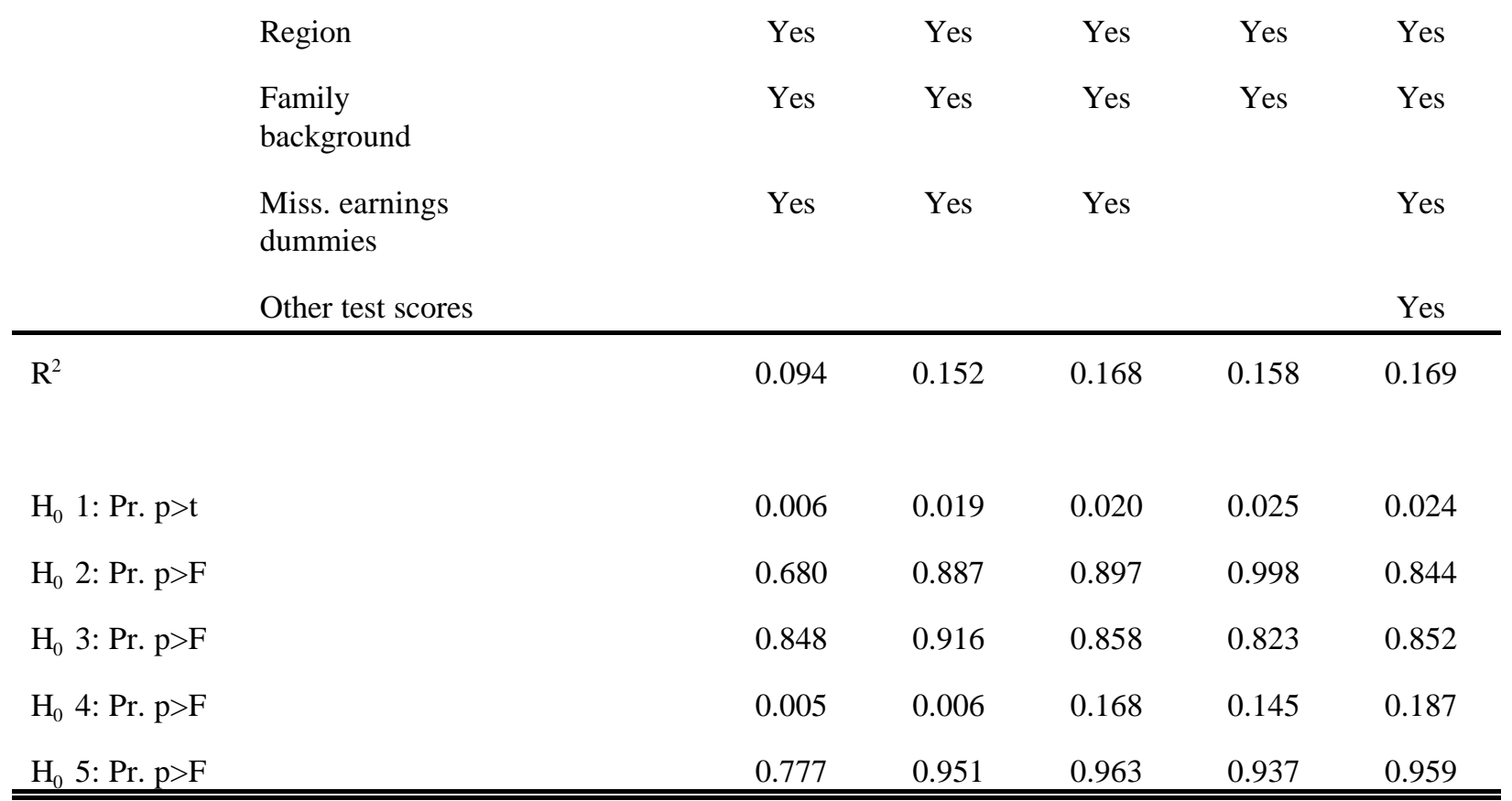

Null \#1: The log earnings of GED-holders in the lowest quartile of math equal the log earnings of permanent dropouts in the lowest quartile of the math score.

Null \#2: The log earnings of GED-holders in the lowest quartile of math and with 11 years of completed schooling equal the log earnings of high school graduates in the lowest quartile of the math score.

Null \#3: The log earnings of GED-holders in the highest three math quartiles equal the log earnings of permanent 
dropouts in the highest three quartiles of the math score.

Null \#4: The log earnings of GED-holders in the highest three math quartiles and with 11 years of completed schooling equal the log earnings of high school graduates in the highest three quartiles of the math score. Null \#5: The log earnings of all GED-holders in the highest three math quartiles are jointly equal. 
Table 7. Regressions of various test score gains, allowing the gain in score to vary by educational credential and timing of GED attainment. (standard errors in parentheses, $* *=$ significant at the 0.01 level, $*=$ significant at the 0.05 level)

\begin{tabular}{|c|c|c|c|c|}
\hline & $\begin{array}{l}\text { Model } 1 \\
\text { Reading } \\
\text { gain }\end{array}$ & $\begin{array}{l}\text { Model } 2 \\
\text { Writing } \\
\text { gain }\end{array}$ & $\begin{array}{l}\text { Model } 3 \\
\text { Science } \\
\text { gain }\end{array}$ & $\begin{array}{c}\text { Model } 4 \\
\text { Math } \\
\text { gain }\end{array}$ \\
\hline & $\mathrm{N}=4910$ & $\mathrm{~N}=4805$ & $\mathrm{~N}=4841$ & $\mathrm{~N}=4887$ \\
\hline Intercept & $\begin{array}{c}0.680 \\
(0.497)\end{array}$ & $\begin{array}{c}0.981 \\
(0.579)\end{array}$ & $\begin{array}{c}0.925 \\
(0.529)\end{array}$ & $\begin{array}{l}-0.865 \\
(0.849)\end{array}$ \\
\hline 10th grade & $\begin{array}{c}0.133 \\
(0.401)\end{array}$ & $\begin{array}{c}0.383 \\
(0.499)\end{array}$ & $\begin{array}{l}-0.327 \\
(0.474)\end{array}$ & $\begin{array}{l}-0.636 \\
(0.680)\end{array}$ \\
\hline 11th grade & $\begin{array}{c}0.610 \\
(0.403)\end{array}$ & $\begin{array}{c}0.246 \\
(0.512)\end{array}$ & $\begin{array}{l}-0.445 \\
(0.472)\end{array}$ & $\begin{array}{l}-0.042 \\
(0.682)\end{array}$ \\
\hline Obtained GED in 1982 or earlier & $\begin{array}{l}0.797^{*} \\
(0.336)\end{array}$ & $\begin{array}{c}2.093 * * \\
(0.426)\end{array}$ & $\begin{array}{l}0.742 * \\
(0.363)\end{array}$ & $\begin{array}{l}0.864 \\
(0.50)\end{array}$ \\
\hline Obtained GED $1983 S 1989$ & $\begin{array}{c}0.464 \\
(0.341)\end{array}$ & $\begin{array}{c}0.551 \\
(0.405)\end{array}$ & $\begin{array}{c}0.385 \\
(0.382)\end{array}$ & $\begin{array}{c}0.169 \\
(0.619)\end{array}$ \\
\hline HS graduate & $\begin{array}{c}1.144 * * \\
(0.386)\end{array}$ & $\begin{array}{c}1.687 * * \\
(0.479)\end{array}$ & $\begin{array}{c}0.282 \\
(0.442)\end{array}$ & $\begin{array}{c}2.207 * * \\
(0.663)\end{array}$ \\
\hline Black & $\begin{array}{l}-0.076 \\
(0.155)\end{array}$ & $\begin{array}{c}0.039 \\
(0.185)\end{array}$ & $\begin{array}{l}-0.235 \\
(0.142)\end{array}$ & $\begin{array}{c}0.507 \\
(0.263)\end{array}$ \\
\hline Hispanic & $\begin{array}{l}-0.138 \\
(0.146)\end{array}$ & $\begin{array}{l}-0.066 \\
(0.158)\end{array}$ & $\begin{array}{l}-0.038 \\
(0.128)\end{array}$ & $\begin{array}{l}-0.290 \\
(0.241)\end{array}$ \\
\hline Other race category & $\begin{array}{c}0.039 \\
(0.258)\end{array}$ & $\begin{array}{l}-0.473 \\
(0.271)\end{array}$ & $\begin{array}{l}0.540^{*} \\
(0.218)\end{array}$ & $\begin{array}{c}0.180 \\
(0.415)\end{array}$ \\
\hline Sophomore writing test score & $\begin{array}{l}-0.022 \\
(0.016)\end{array}$ & & $\begin{array}{c}-0.052^{* *} \\
(0.015)\end{array}$ & $\begin{array}{l}-0.012 \\
(0.026)\end{array}$ \\
\hline Sophomore science test score & $\begin{array}{l}-0.013 \\
(0.018)\end{array}$ & $\begin{array}{c}-0.043^{*} \\
(0.021)\end{array}$ & & $\begin{array}{l}-0.021 \\
(0.030)\end{array}$ \\
\hline Sophomore math test score & $\begin{array}{c}0.010 \\
(0.008)\end{array}$ & $\begin{array}{c}0.002 \\
(0.009)\end{array}$ & $\begin{array}{c}-0.004 \\
(0.007)\end{array}$ & \\
\hline Sophomore reading test score & & $\begin{array}{c}-0.049^{* *} \\
(0.018)\end{array}$ & $\begin{array}{c}-0.006 \\
(0.014) \\
\end{array}$ & $\begin{array}{c}0.041 \\
(0.029)\end{array}$ \\
\hline R-sq & 0.005 & 0.017 & 0.013 & 0.027 \\
\hline $\mathrm{H}_{0}$ 1: Pr. $\mathrm{p}>\mathrm{F}$ & 0.387 & 0.001 & 0.411 & 0.295 \\
\hline
\end{tabular}




\begin{tabular}{lllll}
$\mathrm{H}_{0}$ 2: Pr. $p>F$ & 0.526 & 0.050 & 0.698 & 0.000 \\
$\mathrm{H}_{0}$ 3: Pr. $p>F$ & 0.388 & 0.108 & 0.964 & 0.005 \\
$\mathrm{H}_{0}$ 4: Pr. p>F & 0.094 & 0.046 & 0.558 & 0.000 \\
$\mathrm{H}_{0}$ 5: Pr. p>F & 0.834 & 0.023 & 0.318 & 0.000 \\
$\mathrm{H}_{0}$ 6: Pr. p>F & 0.000 & 0.000 & 0.028 & 0.000 \\
$\mathrm{H}_{0}$ 7: Pr. p>F & 0.055 & 0.000 & 0.010 & 0.000 \\
\hline \hline
\end{tabular}

Null \#1: The relevant gain score of those who obtained their GED in 1982 or earlier is equal to the gain score of those GED-holders who obtained their GED in the period 1983-1989.

Null \#2: The relevant gain score of those who finished the 10th grade and obtained their GED in 1982 or earlier is equal to the gain score of conventional high school graduates.

Null \#3: The relevant gain score of those who finished the 11th grade and obtained their GED in 1982 or earlier is equal to the gain score of conventional high school graduates.

Null \#4: The relevant gain score of those who finished the 10th grade and obtained their GED in the period 198351989 is equal to the gain score of conventional high school graduates.

Null \#5: The relevant gain score of those who finished the 11th grade and obtained their GED in the period 1983 S1989 is equal to the gain score of conventional high school graduates.

Null \#6: The relevant gain score of permanent dropouts who finished the 10th grade is equal to the gain score of conventional high school graduates.

Null \#7: The relevant gain score of permanent dropouts who finished the 11th grade is equal to the gain score of conventional high school graduates. 


\section{References}

Bos, Johannes M., "The Labor Market Value of Remedial Education: Evidence from

Time Series Data on an Experimental Program for School Dropouts," unpublished

Ph.D. dissertation, Robert F. Wagner Graduate School of Public Service, New York University, May, 1995.

Blackburn, McKinley, David Bloom, and Richard B. Freeman. "The Declining Position of Less-Skilled American Males." In A Future of Lousy Jobs, ed. Gary Burtless, 31-67. Washington, D.C.: The Bookings Institution, 1990.

Cameron, Steve V. "Assessing High School Certification for Women Who Dropout." Working Paper, Department of Economics, University of Chicago, 1992.

Cameron, Steve V., and James J. Heckman. "Determinants of Young Male School and Training Choices." In Skill Formation by the Private Sector: International Comparisons, ed. Lisa M. Lynch. Chicago: University of Chicago Press, 1993a.

Cameron, Stephen V., and James J. Heckman. "The Nonequivalence of High School Equivalents." Journal of Labor Economics 11, no. 1 (1993b): 1-47.

Cao, Jian, Ernst W. Stromsdorfer, and Gregory Weeks. "The Human Capital Effect of the GED on Low Income Women." Journal of Human Resources 31, no. 1 (1996): 206-228.

Cave, George, and Johannes Bos. The Value of a GED in a Choice-Based Experimental Sample. New York: Manpower Demonstration Research Corporation, 1994. Paper 
presented at the 106th Annual Meeting of the American Economic Association, Boston.

Ellwood, David. "Teenage Unemployment: Permanent Scars of Temporary Blemishes?" in R. Freeman and D. Wise (eds.), The Youth Labor Market Problem: Its Nature, Causes and Consequences (Chicago: University of Chicago Press, 1982).

Garet, Michael S., Zhongren Jing, and Mark Kutner. The Labor Market Effects of Completing the GED: Asking the Right Questions. Washington, D.C.: American Institutes for Research, 1995.

Juhn, Chinjui, Kevin M. Murphy, and Brooks Pierce. "Wage Inequality and the Rise in Returns to Skill." Journal of Political Economy 101, no. 31 (1993): 410-442.

Katz, Lawrence F., and Kevin M. Murphy. "Changes in Relative Wages, 1963-1987:

Supply and Demand Factors." The Quarterly Journal of Economics 107, no. Feb. 1992 (1992): 33-78.

Kirsch, Irwin S., Ann Jungeblut, Lynn Jenkins, and Andrew Kolstad. "Adult Literacy in America: a first look at the findings of the National Adult Literacy Survey." National Center for Education Statistics Publication \# 93275, August 1993. Maloney, Tim. "Estimating the Returns to a Secondary Education for Female Dropouts." Working Paper No. 100, Department of Economics, University of Auckland, 1992. McMillen, Marilyn, and Phillip Kaufman. Dropout Rates in the United States: 1994. Washington, D.C.: National Center for Education Statistics, 1996. 
Meyer, Robert, and David Wise. "High School Preparation and Early Labor Force Experience.” In R. Freeman and D. Wise (eds.), The Youth Labor Market Problem: Its Nature, Causes and Consequences (Chicago: University of Chicago Press, 1982).

Murnane, Richard J., John B. Willett, and Katherine P. Boudett. "Do High School Dropouts Benefit from Obtaining a GED?" Educational Evaluation and Policy Analysis 17, no. 2 (1995): 133-147.

Murnane, Richard J., John B. Willett, and Katherine P. Boudett. "Does Acquisition of a GED Lead to More Training, Post-secondary Education, and Military Service for School Dropouts?" Industrial Labor Relations Review forthcoming (1997).

Neal, Derek A., and William R. Johnson. "The Role of Pre-market Factors in BlackWhite Wage Differences." Journal of Political Economy 104, no. 5 (1996): 869895.

Passmore, David L. Employment of Young GED Recipients. Washington, D.C.: American Council on Education, 1987, 14.

Reder, Steve. The Nature and Impact of GED Training in Oregon. Portland, Oregon: Northwest Regional Education Laboratory, 1994.

Rich, Lauren. "The Long-Run Impact of Early Unemployment: A Reexamination." Unpublished paper, University of Michigan, 1994.

Soh, Hoon Sahib. "The Rate of Return of the General Equivalency Diploma." 
Unpublished Ph.D. dissertation, Department of Economics, Stanford University, 1996.

Sum, Andrew. Literacy in the Labor Force: Results from the National Adult Literacy Survey. Washington, D.C.: National Center for the Educational Statistics, 1996.

Tyler, John H., Richard J. Murnane, and John B. Willett. Estimating the Impact of the GED on the Earnings of Young Dropouts Using a Series of Natural Experiments. Cambridge, MA: Harvard Graduate School of Education, 1997. Working Paper. 
</ref_section> 


\section{Data Appendix}

\section{High School and Beyond Data}

\section{Sample Selection}

The data used in this paper are from the High School and Beyond national longitudinal survey of 14,825 individuals who were in the $10^{\text {th }}$ grade in 1980 . To be included in our sample, males in the survey had to have participated in both the 1980 base year survey and in the fourth follow-up survey conducted in 1992. In Table 1A below we tabulate the results of this and other sample selection decisions that were made to create the final analytic sample of 4,899 males used in this paper.

Table 1A. Construction of the analytic sample.

\begin{tabular}{|c|c|c|}
\hline Decision Rule & $\begin{array}{l}\text { Number of total individuals not } \\
\text { meeting the criterion }\end{array}$ & $\begin{array}{c}\text { Number of individuals left in the } \\
\text { sample }\end{array}$ \\
\hline Member of base year survey & - & 14,825 \\
\hline Member of $4^{\text {th }}$ follow-up survey & 2,185 & 12,640 \\
\hline $\begin{array}{l}\text { Able to identify the observation as } \\
\text { either a regular high school } \\
\text { graduate, GED-holder, or dropout } \\
\text { as of } 4^{\text {th }} \text { follow-up survey. }{ }^{1}\end{array}$ & 376 & 12,264 \\
\hline $\begin{array}{l}\text { Able to identify the date that GED- } \\
\text { holders left high school and this } \\
\text { date occurs before the date they } \\
\text { obtained their GED }\end{array}$ & 46 & 12,218 \\
\hline Male & 6,338 & 5,880 \\
\hline $\begin{array}{l}\text { Able to identify date that GED- } \\
\text { holder obtained the credential }\end{array}$ & 38 & 5,842 \\
\hline Not in the military in 1992 & 85 & 5,757 \\
\hline $\begin{array}{l}\text { Not in college in both } 1990 \text { and in } \\
1991\end{array}$ & 278 & 5,479 \\
\hline $\begin{array}{l}1990 \text { and } 1991 \text { earnings not both } \\
\text { zero }\end{array}$ & 161 & 5,318 \\
\hline $\begin{array}{l}1990 \text { and } 1991 \text { earnings are within } \\
\text { a plausible range }\end{array}$ & 21 & 5,297 \\
\hline
\end{tabular}


Both 1990 and 1991 earnings are

observed

1980 Sophomore math test score is non-missing

1. Below we discuss the process by which we identified the education status of individuals.

Table 2A gives the distribution of our analytic sample across the different types of educational certification.

Table 2A. Distribution of high school graduates, GED-holders, and permanent dropouts.

\begin{tabular}{lcc}
\hline Type of certification & Frequency & Percent \\
\hline Regular high school graduates & 3,663 & 86.9 \\
GED-holders & 255 & 6.1 \\
Permanent dropouts & $\underline{298}$ & $\underline{7.1}$ \\
Totals & 4,216 & 100.0 \\
\hline \hline
\end{tabular}

\section{Identification of Education Status}

The GED is commonly referred to as a "high school equivalency" certificate. Thus, GEDholders may equate obtaining a GED with graduating from high school, making it unclear how they would answer a survey question about high school completion. There is only one secondaryeducation-status question in the four High School and Beyond surveys that specifically asks respondents whether or not they have earned a GED, and as a result, identification of true GEDholders in the High School and Beyond data is not straightforward. Responses to that question, which was asked in the third follow-up survey (1986), are coded into variable TY18 in the High School and Beyond data.

Our secondary-education-status identification strategy begins with variable TY18. The 831 males and females who identified themselves as GED-holders on this question were all coded as GED-holders in our project, unless high school transcript data disagreed with the self-reported status. Remaining to be resolved were (1) establishing that individuals who called themselves high school graduates on TY18 were, indeed, regular high school graduates, (2) resolving the secondary-education-status of individuals who either indicated they were still in high school in 1986 or whose values on TY18 were missing or invalid, (3) establishing the secondary-education 
status of individuals who did not participate in the third follow-up (1986) survey, and (4) establishing the final (as of 1992) secondary-education status of individuals who indicated on TY18 that they had no diploma or certification as of 1986. In Table 3A below, we present the variables in High School and Beyond that we used to resolve each of these issues.

Table 3A. Variables used to identify secondary-education-status in our analytic sample.

\begin{tabular}{lc}
\hline Issue & High School and Beyond variables \\
\hline Establish initial secondary-education status & TY18 \\
Verify that self-reported high school graduation status \\
on TY18 matches transcript data. \\
$\begin{array}{l}\text { Establish secondary-education status of those with } \\
\text { TY18 missing or invalid. }\end{array}$ \\
$\begin{array}{l}\text { Establish the secondary-education status of those who } \\
\text { either (1) still had an indeterminate education status } \\
\text { as of 1986 or (2) who did not have GED as of 1986, } \\
\text { but who obtained the credential by 1992. }\end{array}$ \\
$\begin{array}{l}\text { Use a 1992 question on whether individuals are } \\
\text { "...still working toward a diploma, GED, or } \\
\text { certification" to identify inconsistencies } \\
\begin{array}{l}\text { Use transcript data and date-left-school data to verify } \\
\text { high school graduation status and clear up further } \\
\text { inconsistencies }\end{array}\end{array}$ \\
\hline \hline
\end{tabular}

Using these variables and a relatively complex algorithm we were able to sort the 14,825 members of the High School and Beyond sample into the categories in Table 4A below.

Table 4A. Distribution of complete (males and females) High School and Beyond sample by secondary-education status.

\begin{tabular}{lcc}
\hline Type of certification & Frequency & Percent \\
\hline Status never positively determined & 623 & 4.0 \\
Regular high school graduates & 11,807 & 79.6 \\
GED-holders & 1,130 & 7.6 \\
Permanent dropouts & 867 & 5.6
\end{tabular}




\begin{tabular}{lcc} 
Conflicts in status, left unidentified & $\underline{398}$ & $\underline{2.7}$ \\
Totals & 14,825 & 100.0 \\
\hline \hline
\end{tabular}

Thus, we are unable to positively identify about 7 percent of the entire High School and Beyond sample. However, when we reconstruct Table 4A using only males who participated in the fourth follow-up (1992), the percentage of individuals for whom we cannot identify the secondary-education status is only about 3 percent, as shown in Table 5A.

Table 5A. Distribution of males in the High School and Beyond who participated in the fourth follow-up survey by secondary-education status.

\begin{tabular}{lcc}
\hline Type of certification & Frequency & Percent \\
\hline Regular high school graduates & 4,959 & 81.1 \\
GED-holders & 478 & 7.8 \\
Permanent dropouts & 469 & 7.7 \\
Conflicts in status, left unidentified & $\underline{209}$ & $\underline{3.4}$ \\
Totals & 6,115 & 100.0 \\
\hline \hline
\end{tabular}

Finally, the discrepancies between the first four rows of Table 5A, above, and the rows of Table 2A, which give the distribution by secondary-education status of our final analytic-sample, are explained by the sample selection criteria of Table 1A.

\section{October 1993 Current Population Survey Data}

\section{Sample Selection}

The data used in Tables 1A and 1B are from the October 1993 Current Population Survey (CPS). To be included in the sample used to construct Table 1A observations had to meet the following criteria:

- not employed in the agriculture, forestry, or fisheries sector,

- $\quad$ last job was not in the military,

- $\quad$ not self-employed, 
- non-missing on CPS variable A-S40 (identification of educational attainment), - $\quad$ age 22 S29, and

- male.

To be included in Table 1B the additional restriction was the individual had to have been a member of the outgoing rotation group in the October 1993 CPS. 


\section{Endnotes}

1. See Passmore (1987), Cameron (1992), Maloney (1992), Cameron and Heckman (1993a, b), Reder (1994), Cave and Bos (1994), Bos (1995), Murnane, Willett, and Boudett (1995), Garet, Jing, and Kutner (1995), Cao, Stromsdorfer, and Weeks (1996), Sum(1996), Soh(1996), Murnane, Willett, and Boudett (1997) .

2. Cameron \& Heckman (1993b), p.24.

3. See endnote \#1.

4. A critical difference between C-H's study and ours lies in the measures of labor market outcome. They use hourly wage and annual hours of work; our data set contains only information on annual earnings.

5. C-H (1993b) summarize much of the evidence in this paragraph.

6. We included in our sample only males who were at least 22 years of age because younger males were likely not to have significant labor market attachment.

7. To make the educational attainment figures in Table 1 comparable to the percentages of males who graduated from high school that are based on the usual CPS or Census data, the percentages of GED recipients and the percentages of males who did not report how they obtained high graduate status (No response) should be added to the percentage of high school graduates in Table 1A. The resulting estimates of the percentages of males who are high school graduates (92 percent for whites, 89 percent for blacks, and 63 percent for Hispanics) are close to estimates reported in the NCES publication, Dropout Rates in the United States: 1994 (McMillen and Kaufman, 1996). 
8. See the data appendix for a description of the calculations used to conclude that most of the non-responders to the question about how they obtained high school graduate status were actually conventional high school graduates rather than GED recipients. 9. As noted in Table 1B, the sample sizes used in estimating the median hourly wages for males with different educational credentials are quite small. Imprecision of estimates may help to explain why the estimated median hourly wage of those "high school graduates" who failed to report how they acquired this status was slightly lower than the estimated median wage of self-reported GED recipients and markedly lower than the estimated median wage of self reported holders of conventional high school diplomas. 10. On average, participants in the JOBSTART program spent 128 hours on educational activities, most of which was GED preparation(Cave \& Doolittle, 1991, p.76).

11. While over 30,000 sophomores participated in the base year and first follow-up surveys, only 14,825 of these individuals were followed into the second, third, and fourth surveys. Of these 14,825 respondents, 13,749 were surveyed in the base year, 14,102 in the first follow-up, 13,682 in the second follow-up, 13,425 in the third follow-up, and 12,640 were surveyed in the fourth follow-up. See the data appendix for details on how the analytic sample was constructed.

12. The NLSY, the data base used in many previous studies of the GED, includes scores from the Armed Services Vocational Aptitude Battery (ASVAB), which more than 90 percent of the sample completed in 1980. At the time participants in the NLSY took this test battery, they were between the ages of 15 and 23, and 40 percent of dropouts who 
obtained a GED by 1994 had already done so. In studying the impact of GED acquisition on subsequent labor market performance, it is inappropriate to use as control variables scores on tests taken after GED acquisition. The reason is that preparation for the GED exam or participation in post-secondary education made possible by GED acquisition may have increased cognitive skills and test scores. If this does occur, then controlling for the ASVAB scores eliminates one mechanism through which GED acquisition may impact on subsequent earnings.

13. We verified that the answers to our research questions were not sensitive to the decision to define the dependent variable as the log of average earnings in 1990 and 1991 instead of as the log of 1991 earnings.

14. The reason we restricted the NLSY sample of dropouts used in the comparisons to the youngest four cohorts is that they are the cohorts that were most similar in age in 1980 to the HS\&B sophomore cohort when it was first interviewed in 1980.

15. C-H (1993b) report a larger difference between the average number of years of schooling completed by permanent dropouts and GED recipients than the difference we report. The explanation lies in the composition of the sample. C-H's NLSY sample included males with as little as six years of completed schooling. All of the school dropouts in our HS\&B sample completed at least nine years of schooling.

16. Eighteen males in our sample whom we classified as "permanent dropouts" obtained a GED in the period 1990-92. According to a publication of the American Council on Education (1995), about 38 percent of the individuals who obtained a GED did so when 
they were age 25 or older.

17. There are several reasons why there is not exactly 25 percent of the analytic sample in each test score quartile. We calculated the cut-off scores defining the test score quartiles using information on both male and females in the High School \& Beyond data set; the analytic sample contains only males. We used sample weights in defining the test score quartiles; we did not use sample weights in calculating the statistics reported in Table 2. Finally, while the test score quartiles were defined using information on all students who completed the test, the analytic sample includes only individuals who reported annual earnings for 1990 or 1991.

18. Fine (1991) makes this argument. Another possible explanation is that the males who obtained a GED prior to the graduation of their cohort were older students who would have dropped out of school in any case. The age distribution of the early GED-recipients does not support this hypothesis, however. Eighty-nine percent of the males who obtained a GED before their cohort graduated from high school were aged 18 or less when they obtained the credential. As indicated in Table 3, 47 percent of the dropouts in the sample who obtained a GED by the end of 1989 did so by the end of 1982 .

19. In our measure of post-secondary education we included credits earned in (noncollege) post-secondary training institutions that provided transcripts. We did so because we could not reject the null hypothesis that the earnings payoff to credits earned in such institutions was the same as the payoff to college credits. Our results are not sensitive to this decision because only four percent of GED recipients in the sample earned a credit at a non-college training institution that provided a transcript.

20. Murnane, Willett, and Boudett (1997) reported that receipt of the GED credential did increase the likelihood that school dropouts would enroll in training programs not 
provided by employers.

21. As explained below and demonstrated in Table 6, the sophomore math score is a much more powerful predictor of earnings at age 27 than are the other sophomore test scores. In fact, when we added the sophomore reading, writing, and science test scores to Model 1, 2, and 3 in Table 5 (which include the sophomore math score), we could not reject the null hypothesis that the coefficients on these additional test scores were all zero The respective $\mathrm{p}$ values associated with the hypothesis test are $0.44,0.61$, and 0.84 . 22. The 42 percent differential is calculated as $\left(\mathrm{e}^{.353}-1\right)$ and the 32 percent differential as $\left(\mathrm{e}^{(.353-074)}-1\right)$

23. We did not use sample weights in fitting the models depicted in Table 5. However, the results using sample weights are quite similar. For example, when Model 1 is estimated using the fourth follow-up sample weights (the HS\&B variable is FU4WT), the coefficient on high school graduate is 0.393 and the coefficient on GED is 0.163. 24. Work experience is measured as the number of months in which an individual had any employment between June 1982 and 1992, divided by 12. The unconditional mean values of work experience for high school graduates, GED recipients, and high school graduates reported in Table 2 are quite close. However, when estimated in a model that controls for family background characteristics and years of post-secondary education, GED recipients are predicted to have .43 more years of work experience than observationally similar permanent dropouts and high school graduates 2.22 more years. 25. In a model that includes a GED by years-of-post-secondary-education interaction and 
a high-school-graduate by years-of-post-secondary-education interaction, we are unable to reject the hypothesis that the estimated coefficients on these two interactions are equal $(\mathrm{p}=0.748)$.

26. Using data from the National Adult Literacy Survey, Sum (1996) also found no statistically significant difference between the earnings of GED recipients and those of high school graduates with no post-secondary education. This result needs to be interpreted cautiously, however, since GED-recipients and conventional high school graduates who do not go on to college are self-selected groups. College is a common path to higher earnings and GED recipients are much less likely to acquire college credits than are high school graduates.

27. Kirsch et al.(1993) report a pattern consistent with our finding that GED recipients earn as much as conventional high school graduates who do not go to college. They find that, on average, GED recipients score as high on the National Adult Literacy Survey as high school graduates who do not go to college.

28. The 37 percent figure was calculated as follows: $\mathrm{e}^{(0.306)}-1$, where .306 is the coefficient on the GED indicator in Model 1 for males in the lowest quartile The results were not substantively different when Model 1 was fitted using sample weights. 29. We thank an anonymous referee for pointing out these two possible sources of bias. 30. Holzer (1996) documents employers' resistance to hiring applicants who have spotty employment records for even low-wage jobs. Meyer and Wise (1982) and Ellwood 
(1982) show that early youth unemployment impacts negatively on workers' subsequent wages. They find little impact on subsequent employment. However, Rich (1994), using more recent data, finds negative effects of early youth unemployment on subsequent employment prospects.

31. Kane \& Rouse (1995), using data from the National Longitudinal Survey of the High School Class of 1972, report that a year of completed post-secondary education was associated with an earnings differential of 4-5 percent. They treat 30 college credits as a year of education. We treat 24 credits (eight 3 -credit courses) as a year of post-secondary education.

32. One model that we fitted parameterized the main effect of tenth grade math score as a fourth order polynomial, and the four math score terms were also interacted with the dichotomous indicators for high school graduate and GED recipient.

33. C-H do not describe in their $1993 \mathrm{~b}$ paper the exclusion restrictions they imposed in estimating their selection model. Instead, they refer the reader to an earlier unpublished version of the paper.

34. As described in the text, more males were excluded from our analytic sample because they did not take the HS\&B sophomore math test than were excluded because they were either in college in 1990 and 1991 or did not report earnings for these years. Thus, even if the indicators of local labor market conditions that $\mathrm{C}-\mathrm{H}$ used had been present in our data set, they would not have solved the primary sample selection problem in our data. 35. Both the 1980 tests and 1982 tests were scaled using Item Response Theory (IRT) so 
that the scores on the two tests are equatable. In 1982 the same tests were administered to school dropouts as to students still in high school. 